\title{
Article
}

\section{Implementing Care Aims in an integrated team}

waterworth, caroline, Willcocks, Stephen George, Roddam, Hazel and Selfe, James

Available at http://clok.uclan.ac.uk/13159/

waterworth, caroline, Willcocks, Stephen George ORCID: 0000-0002-17645951, Roddam, Hazel ORCID: 0000-0002-0637-1801 and Selfe, James (2015) Implementing Care Aims in an integrated team. British Journal of Health Care Management, 21 (1). pp. 36-45. ISSN 1358-0574

It is advisable to refer to the publisher's version if you intend to cite from the work. 10.12968/bjhc.2015.21.1.36

For more information about UCLan's research in this area go to http://www.uclan.ac.uk/researchgroups/ and search for <name of research Group>.

For information about Research generally at UCLan please go to http://www.uclan.ac.uk/research/

All outputs in CLoK are protected by Intellectual Property Rights law, including Copyright law. Copyright, IPR and Moral Rights for the works on this site are retained by the individual authors and/or other copyright owners. Terms and conditions for use of this material are defined in the policies page.

\section{CLoK}

Central Lancashire online Knowledge www.clok.uclan.ac.uk






\section{Implementing Care Aims in an Integrated Team: The impact of culture}

*Waterworth C,

Willcocks SG,

Selfe J,

Roddam H,

\section{Abstract}

This article reports the findings of a pilot study exploring the impact of implementing Care Aims in an integrated community health team. It describes the main findings and discusses the factors which appeared to impact on the implementation and use of the Care Aims approach in these teams.

Care Aims is increasingly being used as a model of care within NHS services, particularly by Allied Health Professionals. The model has been traditionally used in uni-professional teams rather than integrated teams.

This case study suggests Care Aims has potential to support integrated team working. In this study clinicians perceived Care Aims was a model that could improve care for patients, support professionals working together and support self-management. However it is unclear whether it was Care Aims itself or the training and discussion that took place that enabled this team to develop and agree more consistent working practices.

Similar to previous studies, this study has shown how team and professional culture can influence how team members work together and provide care in an integrated way. Team and professional cultures 
are also shown to influence how team members approach and embrace that change. As such Care Aims may be more challenging to some staff groups to implement.

\section{Introduction}

Integrated care continues to be a priority particularly for older people with multiple morbidities. Key messages in a recent report by Goodwin et al (2014) included that the starting point should be a clinical/service model designed to improve care for people; professionals needing to work together in multidisciplinary teams (with clearly defined roles) and that success is more likely if there is a specific focus on working with individuals and informal carers to support self-management.

Care Aims is increasingly being used as a model of care within NHS services, particularly by Allied Health Professionals. Care Aims is a model of practice developed by Kate Malcomess (Malcomess, 2005a) which is designed to support clinicians demonstrate evidence-based practice through systematic reflection. Care Aims focuses on the impact and outcomes of care and requires clinicians to identify their main reason for intervening.

This study offers a new approach to studying Care Aims in the context of integrated care as opposed to previous work which has been undertaken in uni-professional services such as Speech and Language Therapy and Learning Disabilities.

The authors wanted to understand the impact of Care Aims on integrated team working and explore whether Care Aims had the potential to facilitate integrated team working as there appeared to be 
parallels between Care Aims and some of the key messages supporting integrated team working and care.

This paper reports the results of a pilot case study that is part of a wider research project exploring the effect of culture and context on integrated team working for allied health professionals working in primary care settings.

There are many definitions of integrated team working (Maslin-Prothero and Bennion, 2010). For the purpose of this study it is defined as a group of practitioners from different professions/sectors working together on a day to day basis, led by one person, usually based together.

\section{Literature Review}

Allied Health Professionals (AHPs) are acknowledged as being essential to effective integrated care delivery, particularly in the care of older people (The Scottish Government, 2012;) yet similar to Donnelly et al (2013) the literature review found few published studies about integrated team working featuring allied health professionals.

It is acknowledged in the literature that there are various approaches to integration and that no-one model is universally applicable (Curry and Ham, 2010) but that multiple factors contribute to its success. The facilitators and barriers to integrated care and integrated team working being well documented (Hudson, 2006a; Hudson, 2006b; Morrow et al, 2005; Syson and Bond, 2010; Tucker, 2010; Cameron and Lart, 2003; Cameron et al, 2012) with many of these appearing to reflect different dimensions of culture. Kodner (2002) described integration as a culture rather than structure: 
"the glue that bonds the entity together, thus enabling it to achieve common goals and optimal results."

Care Aims is described as a "philosophy that has proven to be extremely versatile and can be adapted to any practice context, team structure or professional group, a standardised way of capturing and communicating clinical reasoning" in addition to focusing on outcomes for clients (Malcomess, 2005). This suggests it has the potential to facilitate the cultural identity described by Petch (2014) which "transcends the traits of particular professions or individuals and provides the most effective basis for the delivery of integrated provision and the achievement of organisational and individual outcomes".

The literature review found few published studies about Care Aims and none could be found in relation to Care Aims and integrated team working. Those found related to uni-professional team working predominantly in the Allied Health Professions (Miller et al, 2013; McCarthy et al 2001; Mowles et al, 2010; Stansfield, 2011).

\section{Method}

The team in this qualitative pilot study covers two urban geographical localities in the north of England. They provide assessment, intervention and advice in relation to a specialist area of community healthcare within the NHS. Whilst the overall team met the inclusion criteria for the study (figure 1 ) as the team included members from nursing, occupational therapy and physiotherapy professions, one locality consisted of nurses only. However the team was in the process of moving to one centralised base. The team members were introduced to Care Aims approximately one year prior to the start of this study. All members of the team were female. The team receives approximately 50 referrals per month with patients seen in their own home, residential/nursing homes and NHS outpatient clinics. 
Figure 1 - Team Inclusion criteria

- The majority of team members have completed the full Care Aims training

- The team includes Allied Health Professions

The team is not undergoing any other major service change e.g. merging with another team

The team manager is supportive of the research project and able to provide access to team members, team members time to fully participate in the study and willing for their team's patients to be approached

- The team is not directly or indirectly managed by the researcher

A questionnaires was distributed to seven members of the team. Consent to participate was implied by return of the questionnaire. The questionnaire also asked respondents if they would participate in a semi-structured interview in addition to completing the questionnaire.

The questionnaire asked respondents to give an account of their understanding, implementation and use of Care Aims. Questionnaire design was based on the critical incident technique (CIT) (Flanagan, 1954). CIT is recognised as a method of analysing culture (Mannion et al, 2008), advocated as a method for studying inter-professional work (Rawson, 1994), and had been employed in studies within healthcare settings (Bendtsen et al., 1999). It is considered a culturally neutral method (Gremler, 2004), 
is context rich and tries to provide a broader understanding of culture within the context it is applied (Jung et al, 2009).

The questions asked respondents to frame their responses in relation to a specific incident or experience which was chosen by the respondent. They were asked to focus on anything that they believed was significant in a positive or negative way. The interview schedule of questions took a similar approach with supplementary questions asked as appropriate.

The dataset was analysed using the process described by Attride-Stirling (2001) to develop thematic networks. As well as enabling a systematic and consistent approach to data analysis this approach will facilitate cross case study comparison in the wider study.

Ethical and organisational research approval was gained from the NHS via Integrated Research Application System (IRAS), University of Central Lancashire and the organisation involved in this study.

\section{Results}

Five team members (71\%) responded to the questionnaires and two of the team also participated in semi-structured interviews. Questionnaire responses were representative of the professions and grades of staff within the team. A nurse and AHP took part in the interviews.

From the data codes were further dissected into coded text segments. 120 coded text segments were identified and these were then grouped and interpreted as basic themes. The 20 basic themes were then clustered and six organising themes identified. The six organising themes were then summarised as global themes (figure 2). 
Figure 2-Global themes

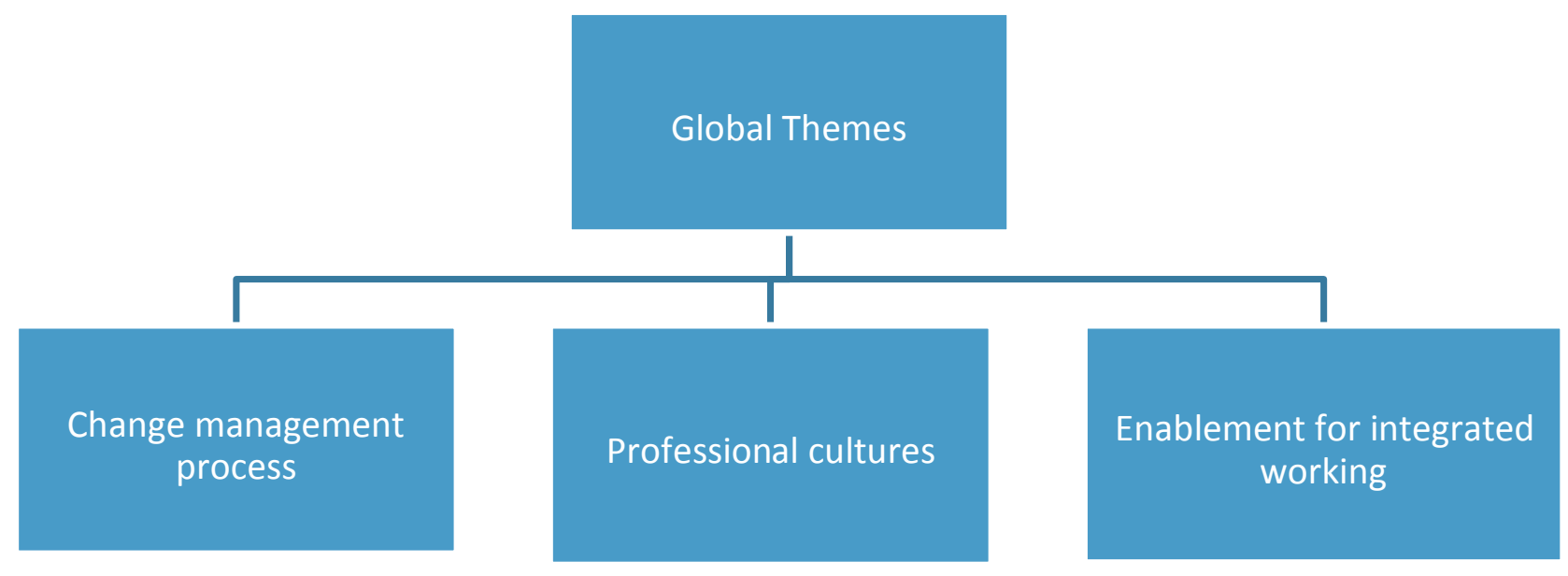

Theme 1: Change management process

Figure 3 - Change management 


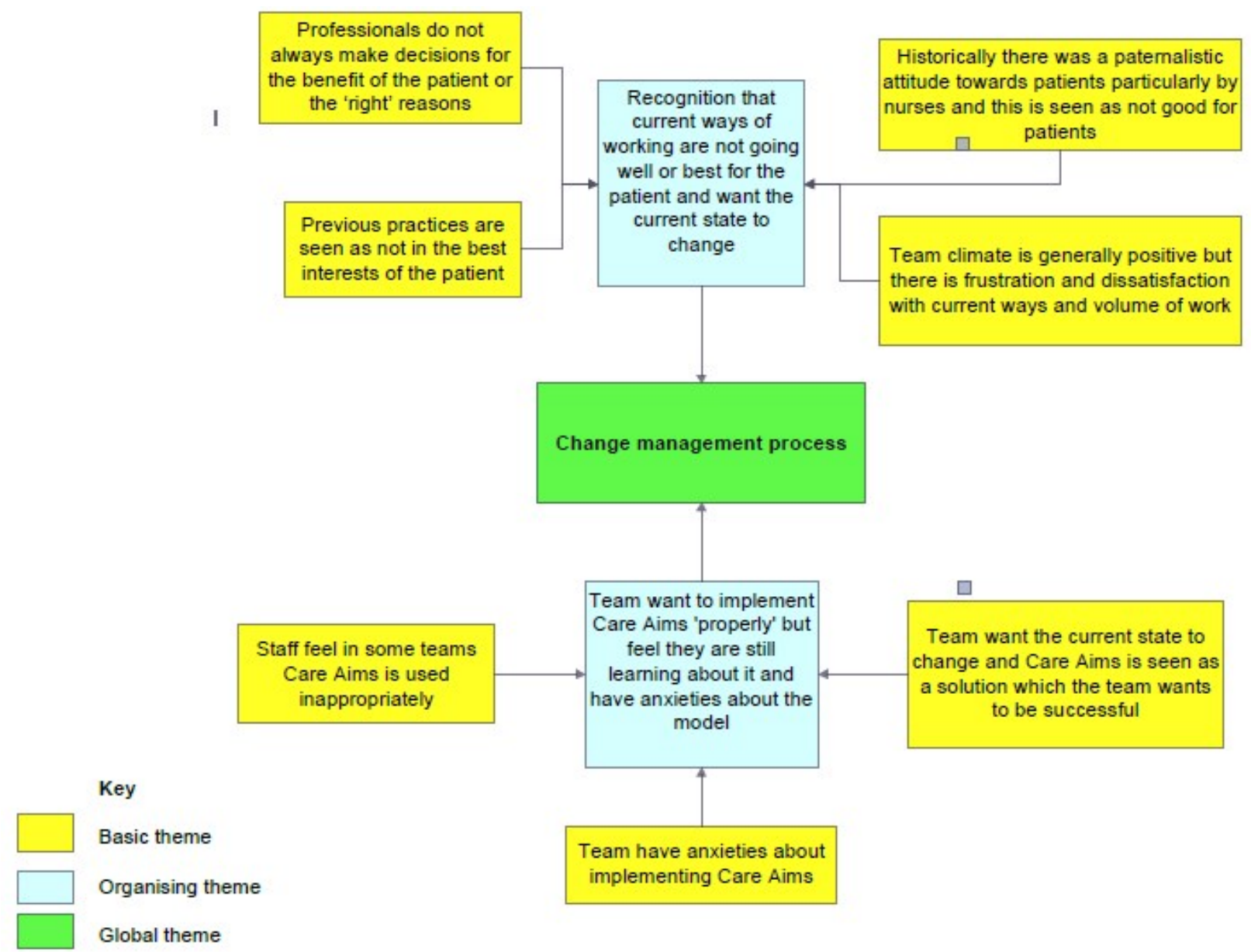

The change management process appeared to be as important as the change itself. The team expressed their dissatisfaction with their current ways of working and volume of work and a desire for the current state to change. There was a recognition that the traditional paternalistic attitude they held towards patients was not in the best interests of patient and at times decisions by professionals had been made not for the benefit of patients. For example members of the team said

"there'll inevitably be one or two cases stick in your mind that you got wrong and you think hell, you know the guilt, clinician's guilt floods in."

And

"it's a dangerous way to practice and I hadn't appreciated that" 
The team wanted to maintain fidelity to Care Aims but felt they were still learning and had anxieties about the model particularly expressing concerns about patients either falling between services or the staff member missing something. The team described how they felt the training was critical as Care Aims was in some respects very different to how they had practiced and thought about the decisions they made previously.

"the first thing with care aims is getting your head around it ....especially for people like me who trained and worked for the NHS for years. And the way I trained was very much focused on what she could do for the patient, ... that that was difficult to some of us"..

Despite all this Care Aims was seen as a solution and the team wanted it to work.

\section{Theme 2: $\quad$ Professional cultures}

Figure 4 - Professional cultures 


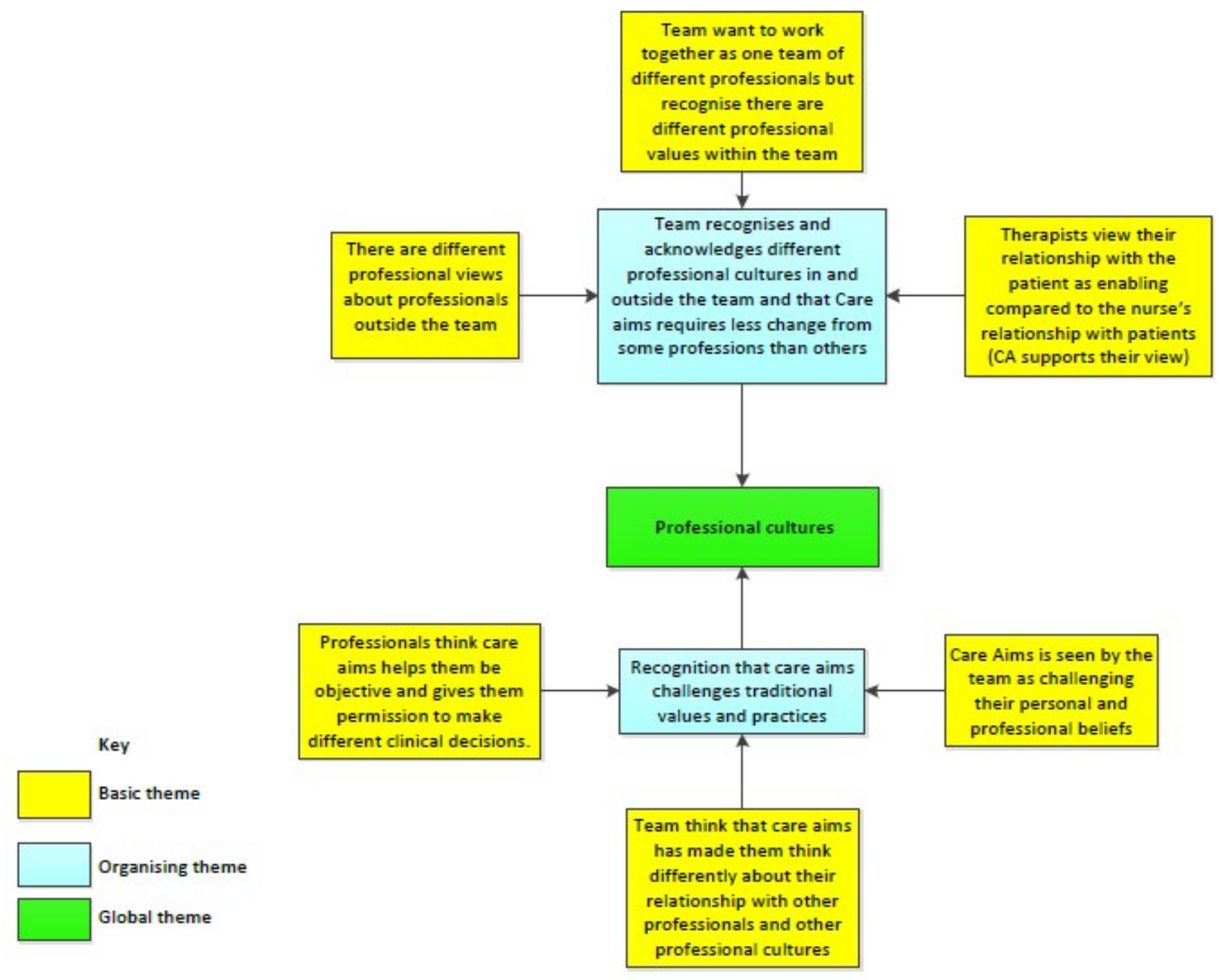

The team recognised that professions have different cultures and values and implied that Care Aims training facilitated their thinking about this. One AHP said

"Certainly myself and the physios see things slightly differently I think than a nursing model... and its no disrespect to nurses. Nurses are very caring, looking after whereas therapists are enablers and I think sometimes there's a clash with it"

Team members described the team differently with the AHP response describing the team as multiprofessional and the other responses describing the team as multi-disciplinary. When asked to describe their role in the team the AHP identified that they provided specialist assessments relating to 
their profession whilst the other respondents were more general in their response and did not refer to their profession in relation to the assessment and treatment they provided.

The role of the patient was also described differently. The AHP felt "equally the person has got to participate" whereas the nurse identified that "I've now come to terms with things now that we can allow patients to make decisions". Questionnaire responses from the nurses in the team included having a "misplaced sense of responsibility for patients", expressing surprise that patients can "take responsibility for their own healthcare - we can trust them".

All the nursing respondents expressed fears that clients/patients could fall between services because of referral criteria which may have contributed to their reluctance to fully adopt the care aims philosophy and assume a more task based approach.

Professional culture appeared to impact on the extent to which individuals were able to support and promote self-management and the level of change required. Responses included "the difference sometimes we're as therapists we're looking at more, getting them to participate in active programs or they might look at a change" with nurses describing their role as "a lot of the time we did just do to patients, who particularly accepted things".

However all the responses gave examples in relation to the respondents own profession with no examples demonstrating an integrated approach to care assessment or planning which may be due to the impact of professional culture. 
AHP responses tended to be more specific about their specialist role compared to the nurses possibly suggesting the AHP has a much stronger professional identity. Given the small number of AHP responses this may be due more to the characteristics of the individuals than professional identity.

The team acknowledged the different professional views in the team but see the value this can bring to the service they provide.

"There's a lot of cross fertilisation of ideas and it does stop and make you think and think about things differently... and the patient will gain from that."

Care Aims appears to have made the team think about their relationship with other professionals and how other professions consider their duty of care. There appears to be recognition that they will approach things differently but Care Aims seems to have given team members a confidence to challenge when they feel they are either receiving inappropriate referrals or working outside their team's scope or duty of care and to consider their relationships with other professionals differently.

\section{Theme 3: $\quad$ Enablement for integrated working}

Figure 5 - Enablement for integrated working. 


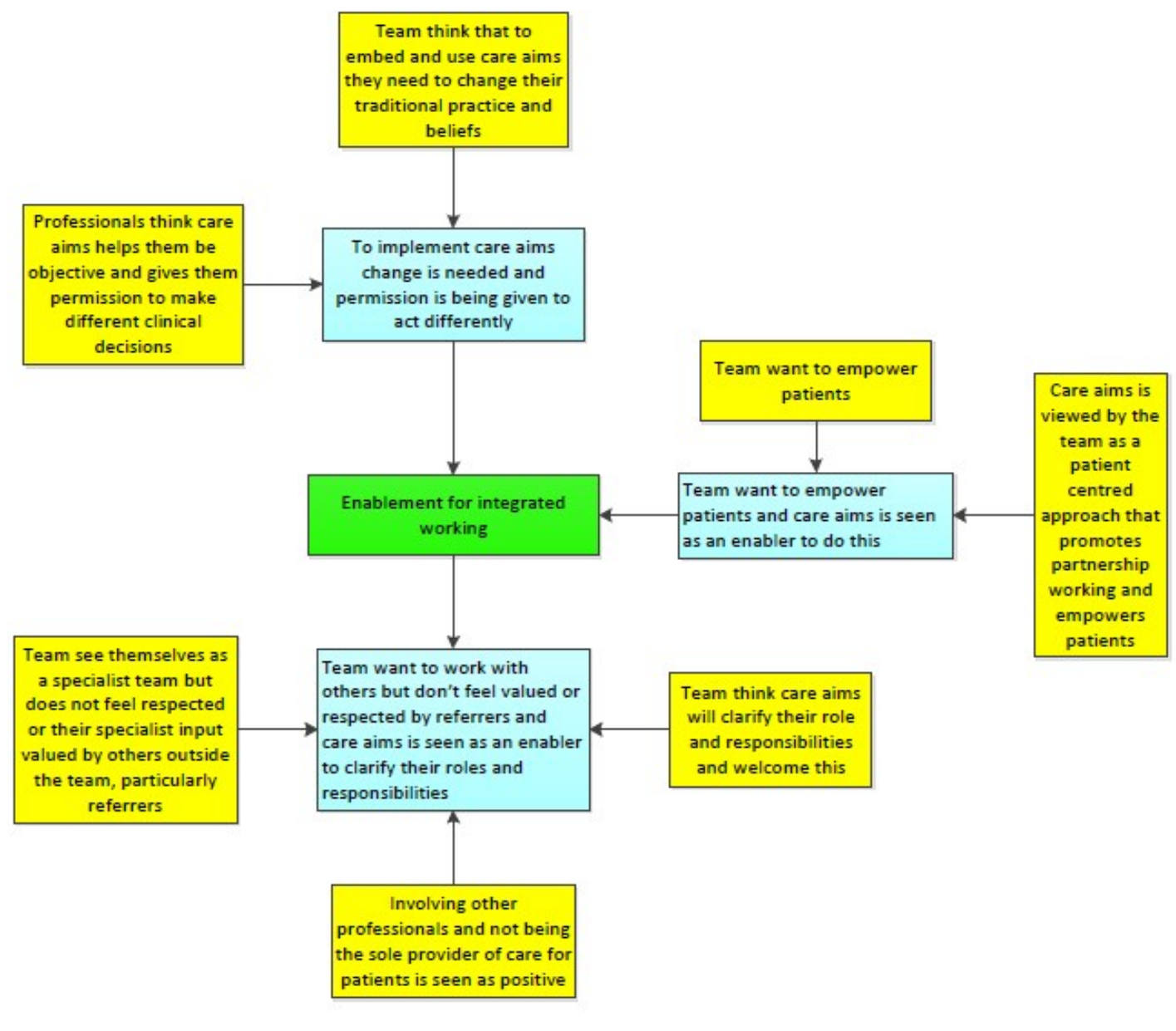

Care Aims appeared to be seen as an enabler for how the team wanted to work, particularly with other professionals and patients but the team recognises that cultural change is required and this needs to be supported by the organization.

The team describe themselves as a specialist services but expressed they did not feel valued or respected by those who refer into their service. At the same time they saw the value and wanted to work with other professionals.

"You are doing the patient a disservice if you don't allow other people to become involved"

Team members viewed the team type, their roles and approach to care differently. Respondents used the terms multi-professional and multidisciplinary to describe their team. 
The team felt that one of the biggest impacts of the Care Aims training was in helping to clarify their role and responsibilities.

"For me the biggest impact was understanding where my role ends so it's not keeping patients on for endless reviews"

Team members identified that to embed Care Aims they needed to change how they worked. Team members described how they felt liberated and had been given permission to act differently, implying that the organisation had given permission to act differently by commissioning Care Aims. "Suddenly I think it becomes quite liberating for a lot of staff because it can be really tough working with patients where there is no improvement but you feel you've reached an impasse you don't have the confidence, the clinical confidence to let go"

Confidence regarding decision making was frequently cited. This may have also come from discussion with other services.

"Other services that are much further down the line than we are, most of them have said its been beneficial and it does change your practice"

The team describe how they wanted to work in the future and described a different relationship with patients, namely with patients as equal partners in their care.

Respondents described the Care Aims as supporting them to work collaboratively with patients "what impact can we help service users manage" ; "looking at the impact of the problem and setting achievable goals and outcomes" to those who choose a different option to that proposed "this was the patient's choice and I had more professional confidence in accepting this". 
One of the difficulties several members of the team described was the challenge referrers found, changing from focusing on the problems the patient had to impact of those problems for the patient so that the team could assess the clinical risk for the patient.

\section{Discussion}

The thematic networks are discussed in the context of the key messages from Goodwin et al (2014).

\section{A clinical/service model designed to improve care for people}

The team appear to view Care Aims as an approach that will improve care for people. Similar to the findings of Goodwin et al (2014), the team described how Care Aims had helped them clarify eligibility criteria for receiving care, a single point of referral, a single and holistic care assessment, a care plan and support from a multi-disciplinary team of professionals. Whilst not explicit it was implied by the team that one member of the team co-ordinated the care provided by the team for a patient.

The shift from problem solving to impact focused thinking which is integral to the care aims approach appeared to lead to different discussions with patients and referrers about possible solutions with potentially longer term benefits for the patient. Unlike a medical model of care, Care Aims is designed to focus on outcome and requires the clinician to understand the meaning of a problem/diagnosis and its impact on the patient to identify interventions (Malcomess, 2005b) i.e. the focus is on the reason for intervening as opposed to what is being done.

Care Aims training appears to have facilitated discussion in the team about different approaches to care and to provide the opportunity for the team to develop and agree more consistent working practices. 
These findings suggest similarities to the case study by Sylvain and Lamothe (2012) where the shared understandings facilitate the team to make sense collectively of events (implementing Care Aims) based on their experience and this has the potential to influence the development of integrated practice going forward that is ingrained in the worked activities of the team.

It is widely acknowledged that cultural change occurs over time and this team are relatively new to using Care Aims and may need more time to consolidate its concepts.

\section{Working together and role clarity}

The literature frequently identifies clarity about roles, team objectives; culture and professional identity and tight role boundaries as factors that affect effective team working (Cameron and Lart, 2003;

Robinson and Cottrell, 2005, Syson and Bond, 2010). Implementing the Care Aims approach appears to have caused the team to think about their own professional culture and those they work with both in and outside their team. Rather than seeing this as divisive the team appear to acknowledge this and use their Care Aims training to reflect on how duty of care and team role may be seen by others and how they can better describe their role and the value they bring to others.

Beales et al (2011) suggest that integrated teams need enough collaborative experience to develop a team culture so that the team culture is the predominant culture during times of change and/or conflict rather than their professional culture. In this case study the majority of members of the team have been part of this team for more than 2 years, some for up to 10 years approximately and articulated different views of team type and role. As the numbers are small in this pilot study, the results may be due to the characteristics of individuals rather than professional identity although Holmesland et al (2010) comment that professional identity is always dependent on personal identity. However Scott et al (2003) 
note that one characteristic of the NHS is the "robustness of each occupational culture" and that the orientation of staff is professional more than corporate. Bloor and Dawson (1994) go further commenting "Of all the allied health professions (physiotherapists and occupational therapists), this group are the most concerned with the image of their profession" (p.285) and therefore their professional identity may be stronger in comparison to their team/organisational identity.

\section{Supporting self-management}

Care Aims asks the clinician to consider the clinical risk a patient may present with. Factors influencing this include awareness and insight of their condition and its risks, capacity to manage and take responsibility for those risks, life circumstances (Malcomess, 2005b). Assessing clinical risk would appear to inform the five core skills required for self-management (figure 6) (Lorig and Holman, 2003).

Figure 6-Core skills for self-management (Lorig and Holman, 2003)

1. Problem solving

2. Decision making

3. Resource utilisation

4. Forming of a patient/healthcare provider partnership

5. Taking action

The organising themes identified that clinicians felt the paternalistic approach to care was not in the best interests of patients and the Care Aims training had challenged them to think differently about this and work with patients to enable and empower them. The results also suggested that the level of change differed according to professional culture in terms of how the relationship with patients was 
viewed e.g. participatory or paternalistic. However in order to support self-management clinicians also have to overcome their anxieties about Care Aims.

The potential of Care aims to support self-care was summarised by one clinician as:

"It's about ensuring that you know and define your role and responsibilities with that patient and that patient is clear about what you can offer them and also where their own personal patient responsibility lies as well in improving their own health condition"

\section{Conclusion}

This pilot case study provides an insight into the impact of culture in one health care team during the implementation of Care Aims. This was a pilot case study so caution should be applied to the findings.

This team had recently started to implement the Care Aims and a longitudinal study comparing team culture pre and post Care Aims implementation may give further insight. Similar to previous studies this case study has given a team member's perspective. To triangulate the data, patients could be asked to participate using a similar approach.

This case study suggests Care Aims has potential to support integrated team working and provision of integrated care. In this study clinicians perceived Care Aims was a model designed to improve care for patients, could support professionals working together and could support self-management although it would appear that there is potential for the team to work in a more integrated way. However it is unclear whether it was Care Aims itself or the training and discussion that took place that enabled this team to develop and agree more consistent working practices. 
Similar to previous studies, this study has shown how team and professional culture can influence how team members work together and provide care in an integrated way. As such Care Aims may be more challenging to some staff groups to implement.

\section{Key points - Review}

- This pilot study suggests Care Aims has potential to support integrated team working

- Care Aims may be more challenging to some professional staff groups than others and consideration should be given to the different professional cultures within the team

- Exploring and addressing the concerns of individuals may facilitate adoption of the philosophy of Care Aims rather than a task based approach

- Teams will need ongoing support to fully implement Care Aims following the initial training. Facilitated discussion to explore and develop their shared understanding may be beneficial.

\section{References}

Attride-Stirling J. (2001) Thematic networks: an analytic tool for qualitative research. Qualitative Research, 1 (3), pp. 385-405, Commission for Health Improvement, England, jennifer.attridestirling@chi.nhs.uk Beales J., Walji R., Papoushek C., Austin, Z. (2011) Exploring professional culture in the context of family health team interprofessional collaboration. Health, 1 (1): 1-12 [online] Available at http://commons.pacificu.edu/hip/vol1/iss1/4/ [accessed 4 February 2012] Bendsten P, Hensing G, McKenzie L, Stridsman A (1999) Prescribing benzodiazepines - a critical incident study of a physician dilemma. Social Science and Medicine 49, pp.459-467 
Bloor G., Dawson P. (1994) Understanding professional culture in organizational context. Organization Studies, 15, (2): 275-295. [online] Available at:

http://oss.sagepub.com/cgi/doi/10.1177/017084069401500205 [Accessed October 29, 2011]. Cameron A.M., Lart, R.A. (2003) Factors promoting and obstacles hindering joint working: a systematic review of the research evidence. Journal of Integrated Care, 11 (2): 9-17

Cameron A.M., Lart R., Bostock L., Coomber C., (2012) Factors that promote and hinder joint and integrated working between health and social care services. London: Care Services Improvement Partnership [online] Available at http://www.scie.org.uk/publications/briefings/briefing41/ Curry, N., Ham, C., (2010) Clinical and Service Integration. London:Kings Fund [online] Available at https://www.kingsfund.org.uk/sites/files/kf/Clinical-and-service-integration-Natasha-Curry-Chris-Ham22-November-2010.pdf [Accessed 25 May 2013]

Donnelly C., Brenchley C., Crawford C., Letts L. (2013) The integration of occupational therapy into primary care: a multiple case study design. BMC Family Practice 2013, 14:60 [online] Available at http://www.biomedcentral.com/1471-2296/14/60

Flanagan J. C. (1954) The critical incident technique. Psychological bulletin, 51(4): 327-58. Available from http://www.ncbi.nlm.nih.gov/pubmed/13177800 [Accessed 5 February 2011]

Goodwin N., Dixon A., Anderson G., Wodchis W. (2014) Providing integrated care for older people with complex needs: lessons from seven international case studies. Kings Fund: London [online] Available at http://kingsfund.koha-ptfs.eu/cgi-bin/koha/opac-detail.pl?biblionumber=111949 Gremler, D., (2004) The Critical Incident Technique in Service Research. Journal of Service Research, 7(1), pp.65-89 
Holmesland A., Seikkula J., Nilsen O., Hopfenbeck M., Erik Arnkil T., (2010) Open dialogues in social networks: professional identity and transdisciplinary collaboration. International Journal of Integrated care. 10 (July - September):1-14 Hudson, B., (2006a) Integrated Team Working: You Can Get it if you Really Want it: Part I . Journal of Integrated Care, 14(1), pp.13-21

Hudson, B., (2006b) Integrated team working part II: Making the inter-agency connections. Journal of Integrated Care, 14(2), pp.26-36

Jung,T., Scott, T., Davies,H., Bower,P., Whalley,D., McNally,R., Mannion,R.,(2009) Instruments for Exploring Organisational Culture: A Review of the Literature. Public Administration Review. Nov/Dec, pp. 1087-1096

Kodner D., Spreeuwenberg C.(2002) Integrated care: meaning, logic, applications, and implications - a discussion paper International. Journal of Integrated Care, 2 (14) pp.

Lorig K., Holman H. (2003) Self management education: History, definition, outcomes and mechanisms. Annals of Behavioural Medicine, 26 (1):1-6

Malcomess K. (2005a) Care Aims Overview [online] Available at http://www.careaims.com/ [Accessed 27 August 2012]

Malcomess K. (2005b) The Care Aims model. In: Anderson C, Van der Gaag A (eds). Speech and Language Therapy: Issues in professional practice. London: Whurr Publishers.

Mannion ,R., Konteh, F., McMurray, R., Davies, H., Scott,T., Jung, T., Bower, P., Whalley, D., McNally, R., (2008) Measuring and Assessing Organisational Culture in the NHS (OC1) National Co-ordinating Centre for the National Institute for Health Research Service Delivery and Organisation Programme (NCCSDO). Retrieved from http://www.netscc.ac.uk/hsdr/files/project/SDO_FR_08-1501-091_V01.pdf [Accessed 7 May 2012]

Maslin-Prothero S. E., \& Bennion, A. E. (2010). Integrated team working: a literature review. International journal of integrated care, 10 (April): 1-11. Retrieved from 
http://www.pubmedcentral.nih.gov/articlerender.fcgi?artid=2883237\&tool=pmcentrez\&rendertype=ab stract [Accessed 4 February 2012]

McCarthy, C., Lacey, R. and Malcomess, K. (2001) An audit of the application of Care Aims across the South West Thames region. International Journal of Language \& Communication Disorders, 36, pp.505510

Millar F., Doherty M., Forster G., McFarlane A., Ogilvie P. (2013) Managing waiting times and providing equitable, family-centred care: a description of four key initiatives from NHS Fife Child Health Occupational Therapy Service (2006-11). The British Journal of Occupational Therapy, 76(8), pp. 379383(5)

Mowles M., van der Gaag A., Fox J., (2010) "The practice of complexity: Review, change and service improvement in an NHS department", Journal of Health Organization and Management, 24 (2), pp.127 144

Morrow, G., Manlin, N., Jennings, T., (2005) Interprofessional teamworking for child and family referral in a Sure Start local programme. Journal of Interprofessional Care. 19 (2), pp.93-101

Petch A. (2014) Delivering integrated care and support. London: Care Services Improvement Partnership [online] Available at http://www.iriss.org.uk/resources/delivering-integrated-care-and-support-insight Rawson, D. ,(1994) Models of interprofessional work. Likely theories and possibilities, in Leathard A. (ed) Going Interprofessional. Working Together for Health and Welfare. London: Routledge.

Robinson M., Cottrell D. (2005) Health professionals in multi-disciplinary and multi-agency teams: changing professional practice. Journal of interprofessional care, 19(6): 547-60.

Scottish Government (2012) AHPs as agents of change in health and social care: The National Delivery Plan for Allied Health Professions in Scotland, 2012-2015. Edinburgh: The Scottish Government. Scott T., Mannion R., Davies H., Marshall M., (2003) Healthcare Performance and Organisational Culture. Radcliffe Medical Press: Oxon

Stansfield J. (2011) Parents with learning disabilities and speech and language therapy. A service evaluation of referrals and episodes of care. British Journal of Learning Disabilities, 40, (3), pp. 169-176 
Sylvain C., Lamothe L. (2012) Sensemaking: a driving force behind the integration of professional practices. Journal of Health Organization and Management, 26 (6): 737-757

Syson G., Bond J. (2010) Integrating health and social care teams in Salford. Journal of Integrated Care, $18(2): 17-24$

Tucker H (2010) Integrating Care in Norfolk - Progress of a National Pilot. Journal of Integrated Care, 18(1) pp.31-38. 